\title{
Glycerol-silicone foams - Tunable 3-phase elastomeric porous materials
}

\author{
Mazurek, P.; Ekbrant, B. E. F.; Madsen, F. B.; Yu, L.; Skov, A. L.
}

Published in:

European Polymer Journal

Link to article, DOI:

10.1016/j.eurpolymj.2019.01.051

Publication date:

2019

Document Version

Peer reviewed version

Link back to DTU Orbit

Citation (APA):

Mazurek, P., Ekbrant, B. E. F., Madsen, F. B., Yu, L., \& Skov, A. L. (2019). Glycerol-silicone foams - Tunable 3phase elastomeric porous materials. European Polymer Journal, 113, 107-114.

https://doi.org/10.1016/j.eurpolymj.2019.01.051

\section{General rights}

Copyright and moral rights for the publications made accessible in the public portal are retained by the authors and/or other copyright owners and it is a condition of accessing publications that users recognise and abide by the legal requirements associated with these rights.

- Users may download and print one copy of any publication from the public portal for the purpose of private study or research.

- You may not further distribute the material or use it for any profit-making activity or commercial gain

- You may freely distribute the URL identifying the publication in the public portal

If you believe that this document breaches copyright please contact us providing details, and we will remove access to the work immediately and investigate your claim 


\section{Accepted Manuscript}

Glycerol-silicone foams - tunable 3-phase elastomeric porous materials

P. Mazurek, B.E.F. Ekbrant, F.B. Madsen, L. Yu, A.L. Skov

PII:

S0014-3057(18)32094-9

DOI: https://doi.org/10.1016/j.eurpolymj.2019.01.051

Reference: EPJ 8831

To appear in:

European Polymer Journal

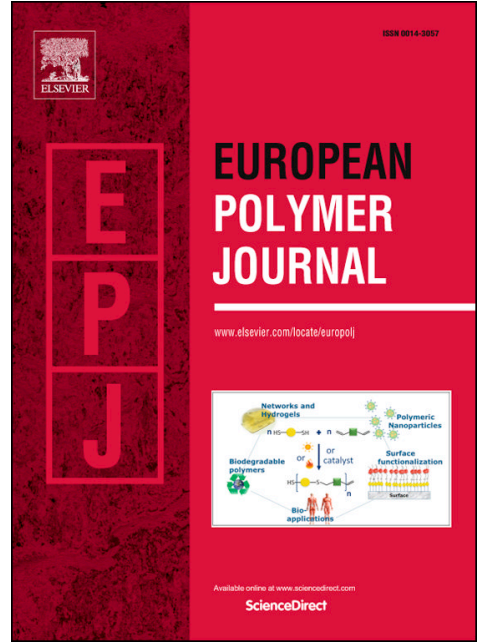

Received Date:

25 October 2018

Revised Date:

17 January 2019

Accepted Date:

23 January 2019

Please cite this article as: Mazurek, P., Ekbrant, B.E.F., Madsen, F.B., Yu, L., Skov, A.L., Glycerol-silicone foams - tunable 3-phase elastomeric porous materials, European Polymer Journal (2019), doi: https://doi.org/10.1016/ j.eurpolymj.2019.01.051

This is a PDF file of an unedited manuscript that has been accepted for publication. As a service to our customers we are providing this early version of the manuscript. The manuscript will undergo copyediting, typesetting, and review of the resulting proof before it is published in its final form. Please note that during the production process errors may be discovered which could affect the content, and all legal disclaimers that apply to the journal pertain. 


\title{
Glycerol-silicone foams - tunable 3-phase elastomeric porous
}

\section{materials}

\author{
P. Mazurek, ${ }^{a}$ B.E.F. Ekbrant, ${ }^{a}$ F.B. Madsen, ${ }^{a}$ L. Yu, ${ }^{a}$ A.L. Skov ${ }^{a^{*}}$ \\ * Corresponding author: al@kt.dtu.dk
}

a Danish Polymer Centre, Department of Chemical and Biochemical Engineering, Technical University of Denmark, DK-2800 Kgs. Lyngby, Denmark.

\begin{abstract}
The time- and cost-efficient production of silicone foams is one of the main challenges of a silicone industry seeking to make these products more competitive compared to traditional foams. Current methods are either too expensive, environmentally harmful or do not provide sufficient control over the foaming process, and therefore intensive research efforts have been launched to tackle this problem. Herein, we present a simple, cheap and environmentally friendly method for preparing a 3-phase silicone-based porous material, the production of which involves a commercial silicone composition, glycerol (waste from bio-diesel production), and an inorganic base. The developed system allows for the precise tuning of foam density and its mechanical properties, thereby creating a robust platform for preparing well-defined porous silicone products.
\end{abstract}

Keywords: glycerol-silicone, A: Polymers, B: Mechanical properties, B: High-temperature applications, C: Elastic properties 


\section{Introduction}

Silicone elastomers are gaining in importance, due to their excellent mechanical properties, thermal stability, low glass transition temperature, UV resistance and low flammability, amongst others, all of which have rationalised the rapid expansion of the silicone product market.[1,2] Interestingly, silicone foams are also known for their superior mechanical and physical properties, in that they offer the additional benefits associated with conventional porous materials.[3-5] However, the market price of silicone foams is currently the main factor obstructing these materials from being applied more extensively despite their advantages over other types of foams.[6] Moreover, silicone foam production is expensive with respect to both the materials used and the processes employed. In this approach we present an alternative, cost-efficient, effective and controllable method for creating silicone foams.

In the most commonly applied method for preparing silicone foams, two simultaneous reactions are employed, namely polyaddition and polycondensation. $[7,8]$ The polyaddition reaction takes place between the hydride groups of a silicone curing agent (CA) and the vinyl groups of silicone-based molecules, which results in the formation of a silicone network. In the case of polycondensation, the CA reacts with a silicone molecule containing hydroxyl groups. As a consequence, hydrogen gas is produced and acts as a blowing agent. The relative intensity and ratio of both reactions determine the morphology as well as the mechanical properties of the resulting foams. Therefore, attractive silicone foams can be produced by optimising the initial substrate mixture by taking into consideration the e.g. stoichiometric ratios of reactive groups (silicon hydride, vinyl and hydroxyl) and the molecular weight of substrates. Other chemical approaches for synthesising silicone foams involve using the polycondensation reaction exclusively or via a PiersRubinsztajn reaction. $[5,7,9]$ 
Several physical methods exist for producing silicone foams, including e.g. employing blowing agents, solvents, non-solvents (e.g. forming high internal phase water-in-silicone emulsions and subsequent evaporation of the non-solvent from the cross-linked structure) and supercritical carbon dioxide.[10-14] However, one particular method has recently gained in importance, albeit mainly within the scientific community, namely the direct templating technique.[15-19] This straightforward method involves using a porous 3D template (e.g. a sugar cube or salt crystals) which is saturated with a silicone pre-polymer. After the silicone has been cured, the template is dissolved and removed, thereby forming a silicone foam. Although this method delivers satisfactory control over porosity and mechanical properties, it is still difficult to transfer it to large-scale production in terms of the construction of the template as well as final washing.

Although various interesting strategies have been developed in order to produce commercially attractive silicone foams, none of them has become a true game-changer in the silicone foam industry. The approach presented herein describes the formation of silicone foams, using recently developed stable glycerol-in-silicone pre-polymer emulsions, which can be cross-linked into elastomers. The only chemicals required are the pristine silicone elastomer and inexpensive, simple reagents. As proven experimentally, there is no foaming when simple glycerol-silicone elastomers are cured at elevated temperatures.[20-22] However, the situation changes when a small amount of base is added to the glycerol phase. It was established that both organic and inorganic bases catalyse the reaction between the silicon hydride groups of the silicone and hydroxyl of glycerol, leading to the formation of gaseous hydrogen, which acts as a blowing agent - as presented in Figure 1. A detailed study on the reaction mechanism can be found in the Supplementary Information. Through this minor composition modification, significant foaming was achieved and eventually led to the 
formation of a unique 3-phase (solid-liquid-gas) material architecture exhibiting stable elastomeric properties.

The aim of this work was to determine parameters influencing the foaming process, and to optimise foaming conditions, in order to obtain reproducible material structures with distinct densities and mechanical properties. Furthermore, the products' thermal properties were investigated to prove the stability of the composite foams.

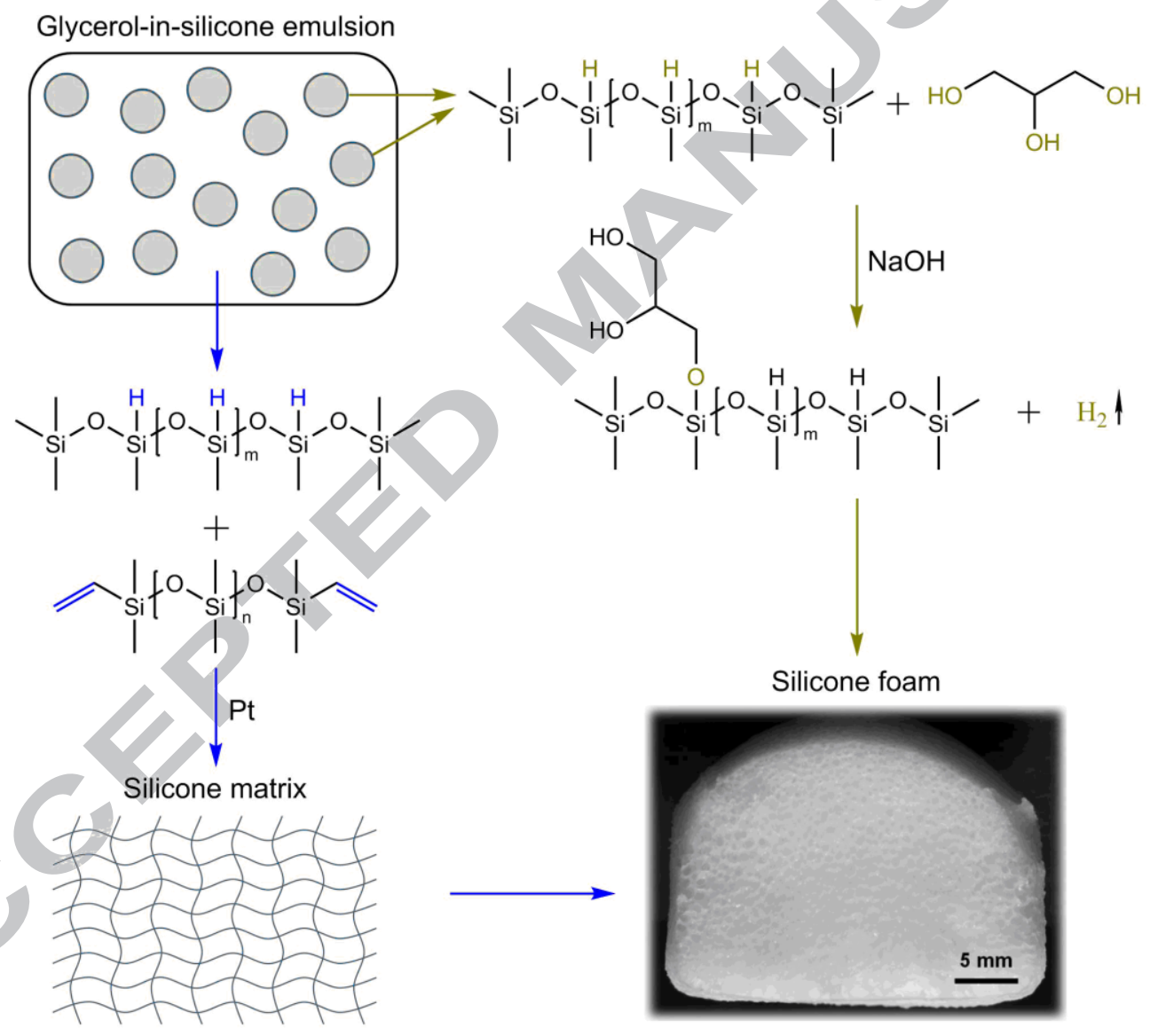

Figure 1. Graphical representation of the chemical and physical processes taking place when foaming glycerol-silicone compositions. A reaction between silicon hydrides and the hydroxyl groups of glycerol, catalysed by sodium hydroxide, leads to the formation of gaseous hydrogen, which in turn acts as a blowing agent. Simultaneously, the reaction between silicon hydrides and the 
vinyl groups of silicones ensures mechanical integrity and a 3-phase (solid-liquid-gas) architecture for the resulting product.

\section{Experimental}

\section{Materials}

A two-component silica-filled hydrosilylation-curing Sylgard 184 silicone kit (abbreviated as S184) was purchased from Dow Corning US. Glycerol was kindly provided by Emmelev A/S, Denmark. Sodium hydroxide, lithium hydroxide and potassium hydroxide were purchased from Sigma Aldrich. Ethanol was purchased from VWR. All products were used as received.

\section{Sample preparation}

First, a given amount of an inorganic base was dissolved in glycerol. Ethanol was added and mixed until a uniform solution was obtained. Subsequently, Sylgard 184 silicone kit pre-polymer was added (different polymer base:curing agent ratios were applied). The composition was speedmixed at 3500 revolutions per minute (rpm) for 25 seconds, using a dual asymmetric centrifuge SpeedMixer DAC 150 FVZ-K. The mixing time was minimised in order to avoid excessive heating of the composition. High shear forces produced by the speed-mixer resulted in the formation of glycerol-in-silicone emulsion, which was subsequently cast onto a round aluminum dish and cured for 30 minutes at an elevated temperature. Each sample was produced and tested in triplicate. The complete sample list, replete with sample names, composition details, curing temperature and basic properties, is presented in Table 1. Based on an example from Sample 1 (reference sample), the foams were prepared as follows. First, $0.088 \mathrm{~g}$ of $\mathrm{NaOH}$ was dissolved in $11 \mathrm{~g}$ of glycerol. 
Subsequently, $0.11 \mathrm{~g}$ of ethanol was added and the solution was mixed vigorously. In the next step, $10 \mathrm{~g}$ of Sylgard 184 was added. The silicone kit was mixed in a 10:1.5 base:curing agent ratio. The complete composition was speed-mixed and cured at $120^{\circ} \mathrm{C}$.

It is important to mention that even small deviations from the described protocol might result in obtaining foams with different parameters, and so high accuracy and strict adherence to the sample preparation protocol is required to obtain reproducible foams. 
Table 1. List of investigated samples with corresponding sample names. The numbers in bold refer to the varied parameter.

\begin{tabular}{|c|c|c|c|c|c|c|c|c|c|c|}
\hline $\begin{array}{c}\text { Sample } \\
\text { No }\end{array}$ & $\begin{array}{c}\text { Sample } \\
\text { name }\end{array}$ & $\begin{array}{c}\mathrm{NaOH} \\
\text { content } \\
{\text { [wt.\% }]^{\mathrm{a}}}^{{ }^{2}}\end{array}$ & $\begin{array}{c}\text { Glycerol } \\
\text { content [phr] }\end{array}$ & $\begin{array}{c}\text { Curing agent } \\
\text { content }\end{array}$ & $\begin{array}{c}\text { EtOH } \\
\text { content } \\
\text { [wt.\% }^{\mathrm{c}}{ }^{\mathrm{c}} \\
\end{array}$ & $\begin{array}{l}\text { Curing } \\
\text { temp. }\left[{ }^{\circ} \mathbf{C}\right]\end{array}$ & $\begin{array}{l}\text { Relative } \\
\text { density }\end{array}$ & $\begin{array}{c}\text { Modulus } \\
{[\mathrm{kPa}]}\end{array}$ & $\begin{array}{l}\text { Foam cell } \\
\text { size }[\mathrm{mm} 2]\end{array}$ & Comments \\
\hline \multicolumn{11}{|l|}{ Reference } \\
\hline 1 & $\mathrm{NaOH}-0.8$ & 0.8 & 110 & 1.5 & 1 & 120 & 0.285 & 88 & 2.00 & no defects \\
\hline \multicolumn{11}{|c|}{ NaOH content } \\
\hline 2 & $\mathrm{NaOH}-0.2$ & 0.2 & 110 & 1.5 & 1 & 120 & 0.610 & $-{ }^{d}$ & - & no defects \\
\hline 3 & $\mathrm{NaOH}-0.4$ & 0.4 & 110 & 1.5 & 1 & 120 & 0.429 & 229 & -2 & no defects \\
\hline 4 & $\mathrm{NaOH}-0.6$ & 0.6 & 110 & 1.5 & 1 & 120 & 0.339 & 138 & -2 & no defects \\
\hline 5 & $\mathrm{NaOH}-0.7$ & 0.7 & 110 & 1.5 & 1 & 120 & 0.309 & 87 & 2.49 & no defects \\
\hline 6 & $\mathrm{NaOH}-0.9$ & 0.9 & 110 & 1.5 & 1 & 120 & 0.267 & 61 & 2.85 & single cell coalescences \\
\hline 7 & $\mathrm{NaOH}-1.0$ & 1 & 110 & 1.5 & 1 & 120 & 0.250 & 42 & 2.73 & single cell coalescences \\
\hline 8 & $\mathrm{NaOH}-1.1$ & 1.1 & 110 & 1.5 & 1 & 120 & 0.240 & 38 & 3.34 & several cell coalescences \\
\hline \multicolumn{11}{|c|}{ Glycerol content } \\
\hline 9 & G90 & 0.8 & 90 & 1.5 & 1 & 120 & 0.351 & 139 & 2.33 & no defects \\
\hline 10 & G100 & 0.8 & 100 & 1.5 & 1 & 120 & 0.325 & 112 & 2.44 & no defects \\
\hline 11 & G120 & 0.8 & 120 & 1.5 & 1 & 120 & 0.303 & 90 & 1.98 & no defects \\
\hline 12 & G137 & 0.8 & 137 & 1.5 & 1 & 120 & 0.282 & 77 & 1.47 & no defects \\
\hline \multicolumn{11}{|c|}{ Curing agent content } \\
\hline 13 & CA1.0 & 0.8 & 110 & 1 & 1 & 120 & 0.311 & 40 & 1.14 & no defects \\
\hline 14 & CA1.25 & 0.8 & 110 & 1.25 & 1 & 120 & 0.292 & 63 & 1.46 & no defects \\
\hline 15 & CA1.75 & 0.8 & 110 & 1.75 & 1 & 120 & 0.282 & 115 & 1.68 & single cell coalescences \\
\hline 16 & CA2.0 & 0.8 & 110 & 2 & 1 & 120 & 0.275 & 121 & 1.82 & single cell coalescences \\
\hline \multicolumn{11}{|c|}{ EtOH content } \\
\hline 17 & EtOH-0 & 0.8 & 110 & 1.5 & $\mathbf{0}$ & 120 & 0.355 & 117 & 1.74 & no defects \\
\hline 18 & EtOH-0.5 & 0.8 & 110 & 1.5 & 0.5 & 120 & 0.324 & 99 & 2.15 & no defects \\
\hline 19 & EtOH-0.8 & 0.8 & 110 & 1.5 & 0.8 & 120 & 0.312 & 86 & 2.68 & no defects \\
\hline 20 & EtOH-0.9 & 0.8 & 110 & 1.5 & 0.9 & 120 & 0.317 & 98 & 1.81 & no defects \\
\hline 21 & EtOH-1.1 & 0.8 & 110 & 1.5 & $1.1>$ & 120 & 0.300 & 87 & 2.08 & single cell coalescences \\
\hline 22 & EtOH-1.2 & 0.8 & 110 & 1.5 & 1.2 & 120 & 0.296 & 87 & 2.27 & single cell coalescences \\
\hline 23 & EtOH-1.3 & 0.8 & 110 & 1.5 & 1.3 & 120 & 0.286 & 79 & 2.34 & several cell coalescences \\
\hline \multicolumn{11}{|c|}{ Curing temperature } \\
\hline 24 & $100^{\circ} \mathrm{C}$ & 0.8 & 110 & 1.5 & 1 & 100 & 0.308 & 96 & 2.06 & no defects \\
\hline 25 & $110^{\circ} \mathrm{C}$ & 0.8 & 110 & 1.5 & 1 & 110 & 0.308 & 99 & 1.75 & no defects \\
\hline 26 & $130^{\circ} \mathrm{C}$ & 0.8 & 110 & 1.5 & 1 & 130 & 0.282 & 80 & 1.63 & no defects \\
\hline 27 & $140^{\circ} \mathrm{C}$ & 0.8 & 110 & 1.5 & 1 & 140 & 0.283 & 76 & 1.55 & no defects \\
\hline \multicolumn{11}{|c|}{ Other samples } \\
\hline $28^{\mathrm{e}}$ & LiOH-0.4 & 0.4 & 110 & 1.5 & 1 & 120 & 0.38 & 207 & - & no defects \\
\hline $29^{f}$ & KOH-0.4 & 0.4 & 110 & 1.5 & 1 & 120 & 0.56 & $-{ }^{d}$ & - & no defects \\
\hline 30 & S184 & - & $-2>0$ & - & - & 120 & - & - & - & pure elastomer \\
\hline
\end{tabular}

${ }^{\mathrm{a}} \mathrm{NaOH}$ content dissolved in glycerol in wt.\% 


\section{${ }^{\mathrm{b}}$ Weight parts of curing agent per 10 weight parts of base polymer}

${ }^{c}$ Ethanol content dissolved in glycerol in wt.\%

${ }^{\mathrm{d}}$ The relative density was insufficient to test the specimen following the applied protocol

${ }^{\mathrm{e}} \mathrm{LiOH}$ was used instead of $\mathrm{NaOH}$

${ }^{\mathrm{f}} \mathrm{KOH}$ was used instead of $\mathrm{NaOH}$ 


\section{Methods}

An FEI Quanta 200 ESEM FEG scanning electron microscope (SEM) was used to evaluate the morphologies of the produced foams. Prior to testing, the cross-sections were coated under vacuum conditions and a current of $20 \mathrm{~mA}$ was applied for $5 \mathrm{~s}$ to give a $2 \mathrm{~nm}$-thick gold layer, using a high resolution Cressington 208HR sputter coater. Foam images were taken with a Panasonic Lumix G2 digital camera, and the compression modulus was obtained using TA Instrument ElectroForce 3220. A $45 \mathrm{~N}$ load cell was used in order to ensure high measurement accuracy. Round samples with a diameter of $44 \mathrm{~mm}$ and $17 \mathrm{~mm}$ in thickness were compressed at a rate of $0.1 \mathrm{~mm} / \mathrm{s}$. Three samples of each type were tested and the results averaged. A Keyence VHX-6000 digital microscope was used to examine the samples' cross-sections. TGA Discovery from TA Instruments was used to perform thermogravimetric analysis (TGA). Specimens were tested under nitrogen in an isothermal mode $\left(200{ }^{\circ} \mathrm{C}\right.$ and $300{ }^{\circ} \mathrm{C}$ for 5 hours $)$ and a temperature ramp mode $\left(10^{\circ} \mathrm{C} / \mathrm{min}\right)$.

\section{Results and Discussion}

\subsection{Tuning foam morphology - influence of various synthesis parameters}

Foam synthesis experiments revealed that different sample morphologies can be obtained by introducing slight modifications to the synthesis protocol. In this section, some of these factors are described and evaluated with the aim of outlining a clear path for preparing silicone foams with desired morphology and mechanical properties.

3.1.1. Influence of sodium hydroxide content in the glycerol phase 
First, the influence of the base (sodium hydroxide) concentration in the glycerol phase was studied. Images presented in Figure 2 clearly indicate that a strong relationship between foam density and the amount of the base exists, in that the higher the base content, the lower the density. Moreover, foam pore size increases in line with increased base loading. More details on foam pore size can be found in Table 1 and in Supplementary Information. It is hypothesised that a higher amount of ions in the glycerol phase will accelerate the reaction rate between glycerol hydroxyl groups and silicon hydride groups in the silicone curing agent. Consequently, faster hydrogen gas evolution is observed, which leads subsequently to obtaining foams with lower densities and larger pores. Samples with lower densities tend to possess structural defects in the form of cell coalescences (mainly on the edges of samples). It is considered that low base concentration allows for obtaining more uniform samples with better-defined morphologies, as the foaming process is less vigorous.

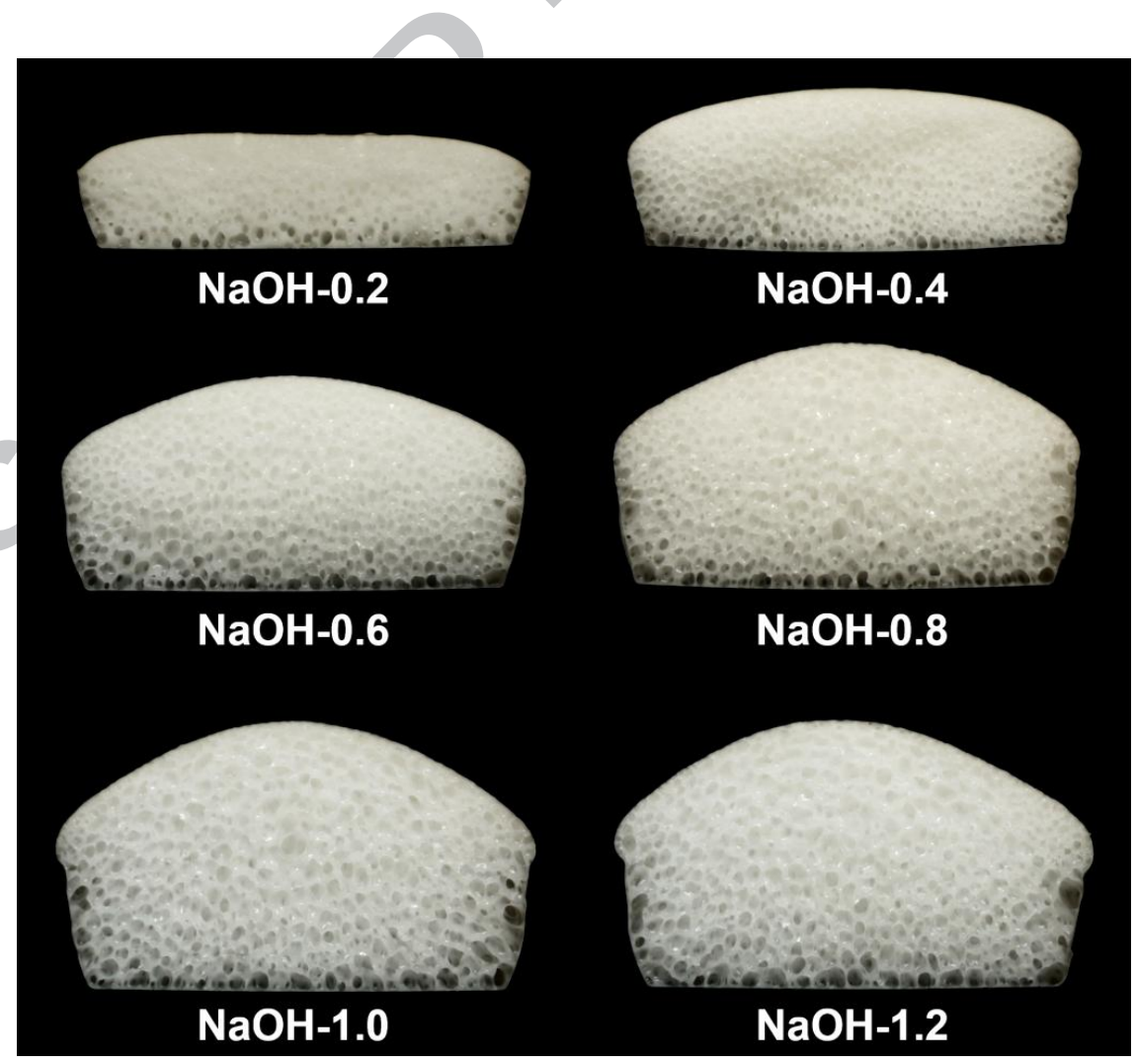


Figure 2. Cross-sections of round foams prepared using standard synthesis parameters with varied base concentrations.

The micromorphology of the samples was studied using various microscopy techniques. The digital microscopy images of a sample $\mathrm{NaOH}-0.4$ presented in Figure 3A-B indicate that it has a structure typical of a closed-cell foam with all voids clearly separated with the elastomer. However, one sample, namely NaOH-0.8 (see images in Figure S7 in Supplementary Information), exhibits an increased amount of interconnected cells, which is typical for open-cell foams. Moreover, in Figure 3B, small glycerol droplets deposited on the foam can be observed. As reported previously, the glycerol droplets are released from glycerol-silicone materials when a sample is stretched or compressed.[20] It is considered that this phenomenon could be utilised in smart drug delivery systems as a possible active substance-release mechanism. Moreover, the released glycerol might result in an oily feeling making its perception closer to a mammal alike tissue compared to purely polymeric materials. Images in Figure 3C-D and Figure 4 indicate uniform glycerol droplet dispersion and narrow droplet size distribution throughout the silicone. It is evident that the micromorphology of the glycerol-silicone foams resembles the micromorphology of the glycerolsilicone elastomers despite the high-temperature curing and intense foaming process, which might potentially deteriorate the composite's structure. 


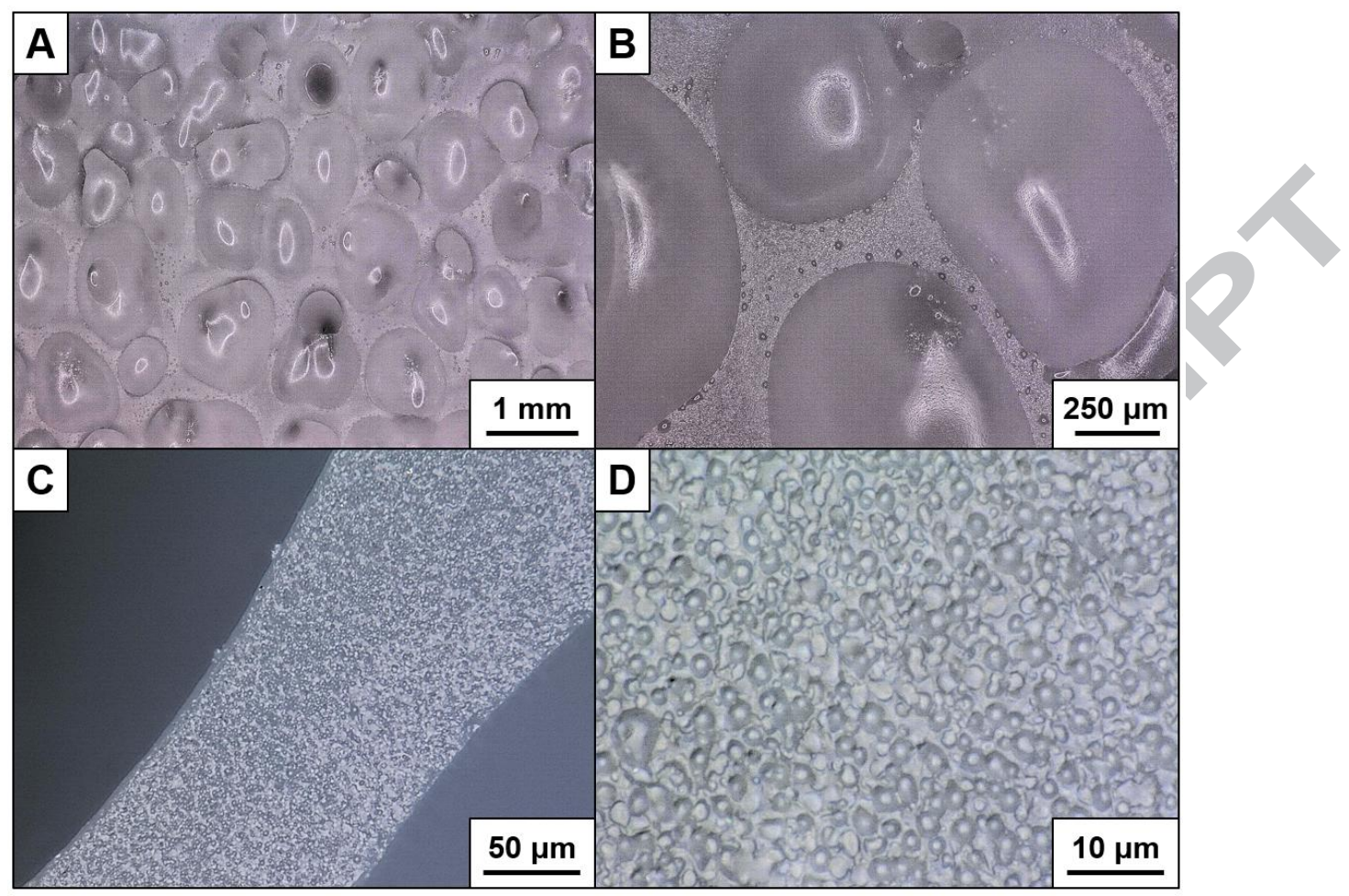

Figure 3. Digital microscopy images of the sample $\mathrm{NaOH}-0.4$ cross-sections taken at various magnifications. Images $\mathrm{A}$ and $\mathrm{B}$ present the foam architecture, while images $\mathrm{C}$ and $\mathrm{D}$ demonstrate the micromorphology of the foams, typical for glycerol-silicone elastomers.

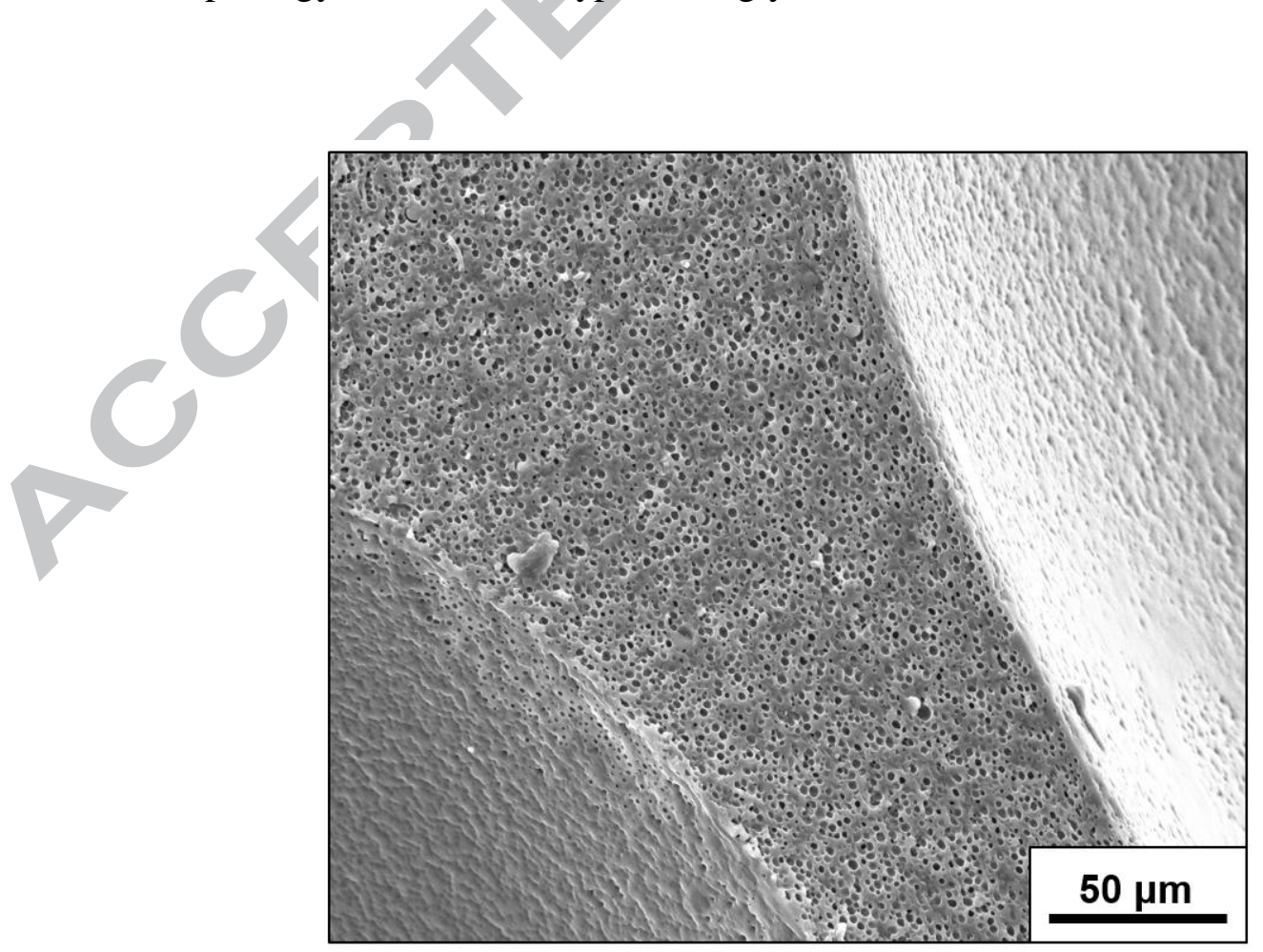


Figure 4. SEM image of a sample $\mathrm{NaOH}-0.8$ cross-section demonstrating the homogeneous micromorphology of glycerol-silicone foams.

The relative density and the compression modulus of each sample were measured for three specimens. Relative density ( $\left.\rho_{\text {rel }}\right)$ was calculated using:

$$
\rho_{\text {rel }}=\frac{\rho_{\text {foam }}}{\rho_{\text {emulsion }}}
$$

where $\rho_{\text {foam }}$ is the density of the foam and $\rho_{\text {emulsion }}$ is the density of the emulsion used to prepare the foam. Conventionally the relative density is referred to a solid polymer density and not to the emulsion density used to produce foams. However, in this particular case glycerol is present also in the resulting foam. Therefore the emulsion is considered here as a point of reference when determining the relative density of the produced foams. The density of the foam was measured by comparison of the sample mass to sample volume (calculated by analyzing the sample dimensions) after the foaming process. The relative density decreases significantly when increasing the base content, as presented in Figure 5. Sample $\mathrm{NaOH}-0.2$ has a relative density of 0.61 , while sample $\mathrm{NaOH}-1.1$ has a relative density of 0.24 , which proves that by controlling the base content, glycerol-silicone foams in a broad density range can be obtained. Moreover, the compression modulus also decreases significantly when increasing the base content. The shape of the relative density and modulus curves as a function of the base content are nearly identical, thereby indicating an almost linear correlation of relative density and modulus, as presented in Figure 5's inset. The study proves that the relative density and compression modulus can be tuned precisely using this method, which is a significant advantage of this system. A representative compression test curve is presented in the Supplementary Information. 
The mechanical properties of several samples were tested 6 months after their preparation. In all cases, the compression modulus was not compromised, which indicates excellent material stability when stored at room temperature over an extended time period despite the potentially negative effect of $\mathrm{NaOH}$ in the foam structure.

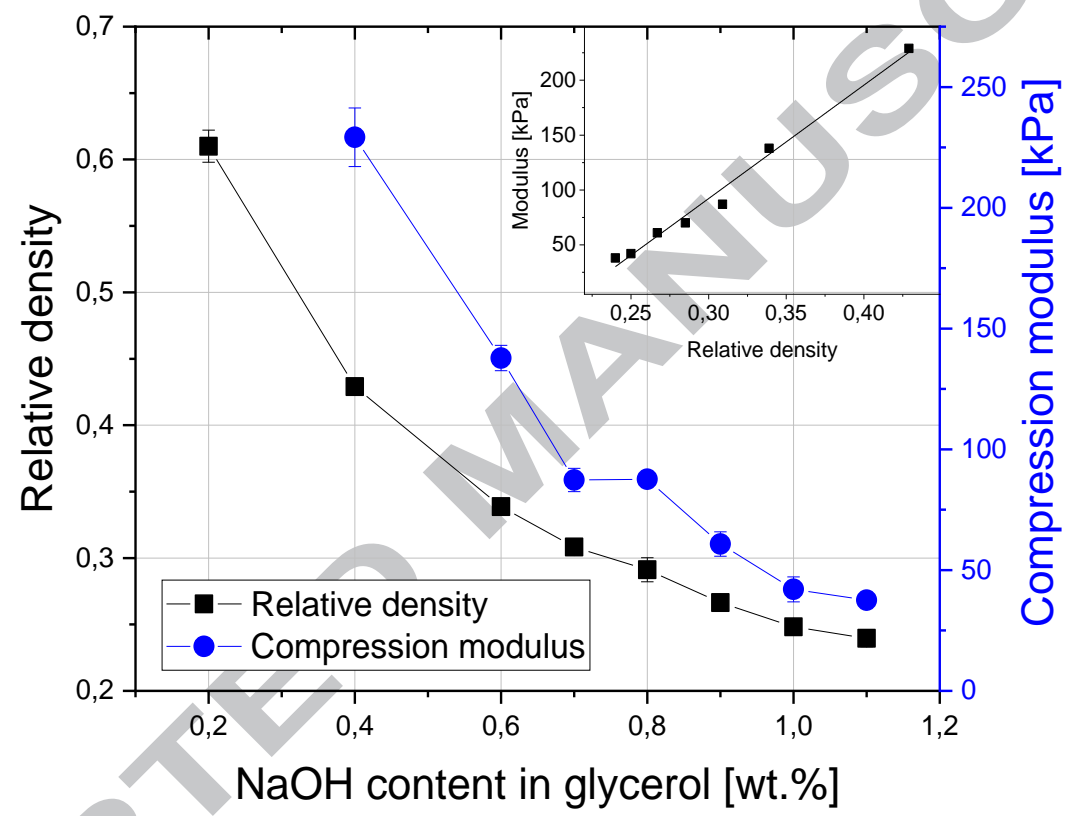

Figure 5. Relative density and compression modulus of glycerol-silicone foams with different sodium hydroxide contents in the glycerol phase. In the inset, the compression modulus and relative density relationship is presented.

\subsubsection{Influence of other factors on the foaming process}

Aside from the base content in the glycerol phase, multiple other parameters were also found to affect the foaming process. Graphs presented in Figure 6 summarise the influence of glycerol content, curing agent content, ethanol content and curing temperature on the relative density and compression modulus of the investigated foams. In this study, the standard composition was used as 
a starting formulation, and one parameter at a time was modified. Samples with increased amounts of glycerol tend to possess lower densities, as presented in Figure 6. The glycerol-silicone interface per volume is larger for samples with higher glycerol loading, assuming that the average glycerol domain size decreases only slightly in line with increasing glycerol loading.[22] The reaction between the hydroxyl groups of glycerol and the silicon hydride groups of the curing agent takes place on the interface between the two phases, in which case the lower density of foams with higher glycerol loadings is understandable. As reported previously, emulsions with higher glycerol loadings have significantly higher viscosities[20], which are believed to hinder the foaming process. Therefore, it can be hypothesised that a compound improving the flow properties of the investigated glycerol-silicone emulsions will significantly improve the foaming process.

Adding higher amounts of the curing agent increases the number of silicon hydride groups, which is an intuitive way to boost the extent of developed hydrogen gas during foaming. However, increasing curing agent content results in a significant enlargement of the average pore size, and therefore low curing agent contents are advantageous for producing small-pore foams. Moreover, variations in curing agent content appear to be the most efficient way to control the modulus of the foam - the more curing agent, the stiffer the foams, as seen in Figure 6.

The use of low-vapour-pressure liquids is a common method employed to produce or support porous material fabrication.[23,24] Therefore, the influence of ethanol dissolved in the glycerol phase on the foaming process was investigated. It was found that ethanol used in incremental concentrations $(0.5-1 \%$ in glycerol $)$ can indeed boost the foaming process, leading to the formation of foams with well-defined structures. Ethanol added in concentrations higher than $1 \%$ results in the formation of porous structures, albeit usually with very large and irregular pores. It is believed that other liquids can also be applied. However, the right balance between the temperature 
of the foaming process and the boiling point of a selected liquid has to be found, in order to ensure controlled foaming.

Controlling the curing temperature is another way of tuning the foaming. Temperature directly affects the hydrosilylation reaction of the applied silicone elastomer[25], the evaporation rate of ethanol present in the composition and, probably, the condensation reaction between the hydroxyl and silicon hydride groups. The experiments conducted for this study indicate that higher temperatures lead to the formation of lower-density foams for the investigated formulations. However, it has to be stressed that this tendency applies purely to this specific formulation and should be evaluated separately for other compositions comprising different contents of hydrosilylation reaction catalysts and inhibitors.

In this section, various parameters influencing the foaming process have been described and evaluated. It is believed, however, that there are more factors that might influence foaming, and therefore it has to be remembered that small deviations from the described procedure might affect the final product's properties. 

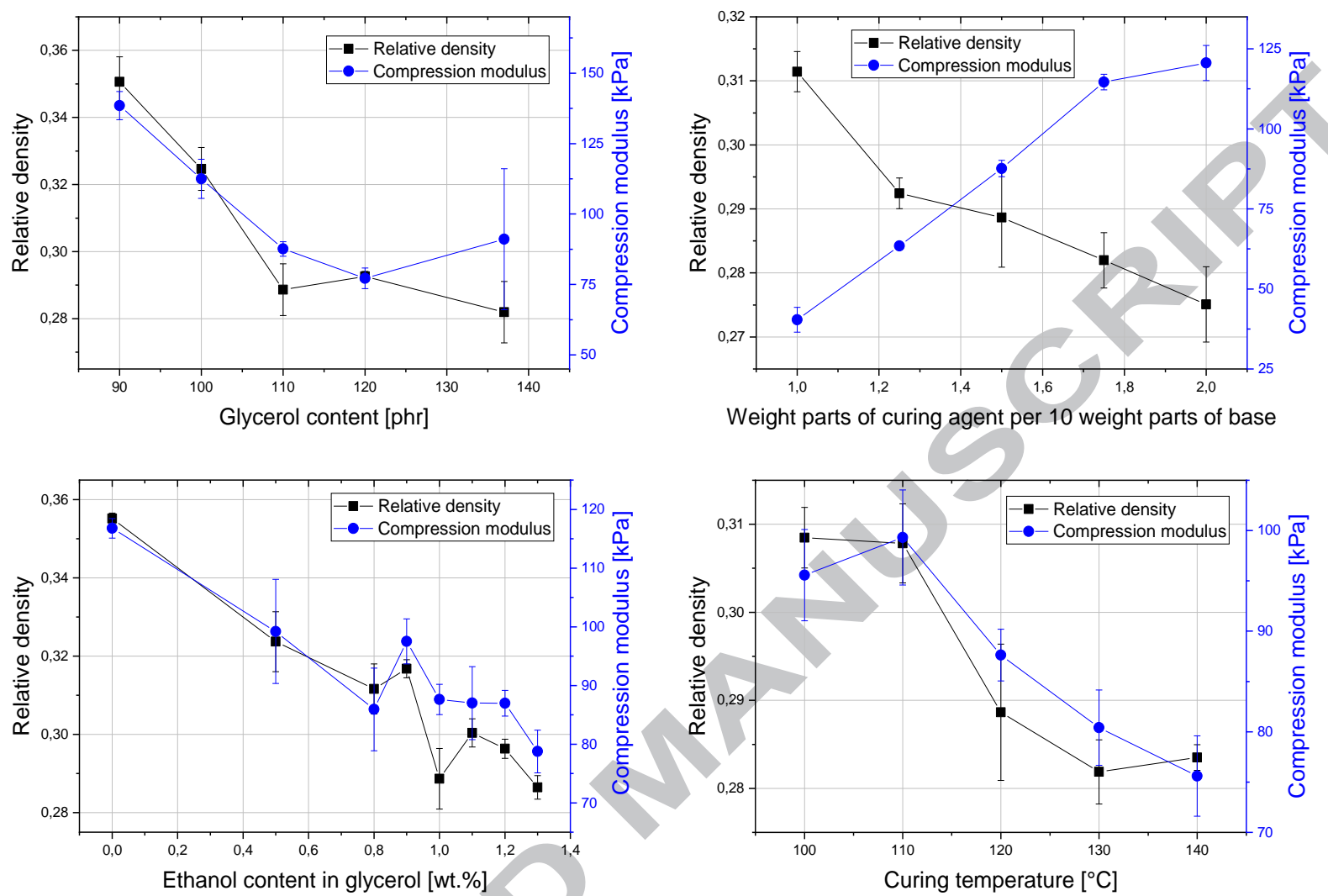

Figure 6. Relative density and compression modulus of foams as a function of glycerol loading (top left), curing agent content (top right), ethanol content (bottom left) and curing temperature (bottom right).

\subsection{Thermal stability of the glycerol-silicone foams}

Silicone elastomers and silicone foams exhibit particularly good thermal stability, which they owe to high dissociation energy and low-energy barriers to siloxane bond rotation.[26] It is known that this property might be compromised by the presence of acids and bases, which might trigger a random chain scission of the siloxane bond and eventually lead to the loss of mechanical stability.[27] The presence of a base is essential for the successful foaming of the systems discussed 
herein, and therefore investigating the thermal stability of the glycerol-silicone foams using thermogravimetric analysis is a key study in proving the reliability and robustness of the presented system.

First, the influence of the various synthesis parameters described above on the thermal stability of foams was investigated. Results presented in Figure 6 showcase the presence of four main processes taking place as the foams were heated up. The first mass loss, taking place from room temperature up to about $100^{\circ} \mathrm{C}$, corresponds to the evaporation of ethanol from the glycerol phase. The sample EtOH-0 also exhibits a mass loss in this region, although no ethanol was used to prepare this composition. The hygroscopic nature of glycerol makes it nearly impossible to eliminate fully water from the system, and so it is believed that the first peak resembles the evaporation of ethanol (if added) and water. The second mass loss occurs at temperatures between $100^{\circ} \mathrm{C}$ and $275^{\circ} \mathrm{C}$ and is related to glycerol evaporation. The vapour pressure of glycerol is negligible at room temperature and remains very low even at elevated temperatures.[28] However, the presence of ethanol and water is expected to decrease significantly the vapour pressure of the mixture, and so glycerol evaporation starting already from $100^{\circ} \mathrm{C}$ is not surprising. Moreover, it is believed that early evaporation onset is supported additionally by the extremely high surface area of the glycerol phase. Interestingly, the evaporation of the liquids (mainly glycerol) can be considered an efficient way of decreasing the density of the foams even further, as about $50 \%$ of the total foam volume is lost during the heating process, without any signs of polymer degradation below $200{ }^{\circ} \mathrm{C}$. It is expected that this method could yield foams with relative densities of about 0.12 .

Silicone network degradation starts at around $350{ }^{\circ} \mathrm{C}$ and reaches the first peak at around $390{ }^{\circ} \mathrm{C}$. It is anticipated that in this process the sol fraction of the PDMS network is degraded.[29] The second and major degradation process reaches a peak at $470{ }^{\circ} \mathrm{C}$, which is very similar to the degradation 
peak of pure Sylgard 184, which occurs at around $510{ }^{\circ} \mathrm{C}$ (TGA thermograph not shown, due to significant scattering of the curve).

Samples with varying amounts of sodium hydroxide were additionally exposed to isothermal TGA treatment at $200{ }^{\circ} \mathrm{C}$ and $300{ }^{\circ} \mathrm{C}$ for 5 hours. The results presented in Figure 7 confirm a multi-stage mass loss process. All samples analysed at both temperatures initially lost ethanol and water and subsequently glycerol. Thereafter, samples tested at $200{ }^{\circ} \mathrm{C}$ reached a steady state, while a slight mass decline was observed for samples tested at $300{ }^{\circ} \mathrm{C}$. Pure Sylgard 184 silicone samples exhibited an almost identical mass decline during isothermal treatment at $300{ }^{\circ} \mathrm{C}$, which confirms that the presence of sodium hydroxide in the glycerol phase does not compromise the long-term thermal stability of the glycerol foams, even at temperatures as high as $300{ }^{\circ} \mathrm{C}$.

The TGA analysis indicated that the amount of sodium hydroxide applied within the investigated range does not influence the thermal stability of glycerol-silicone foams.
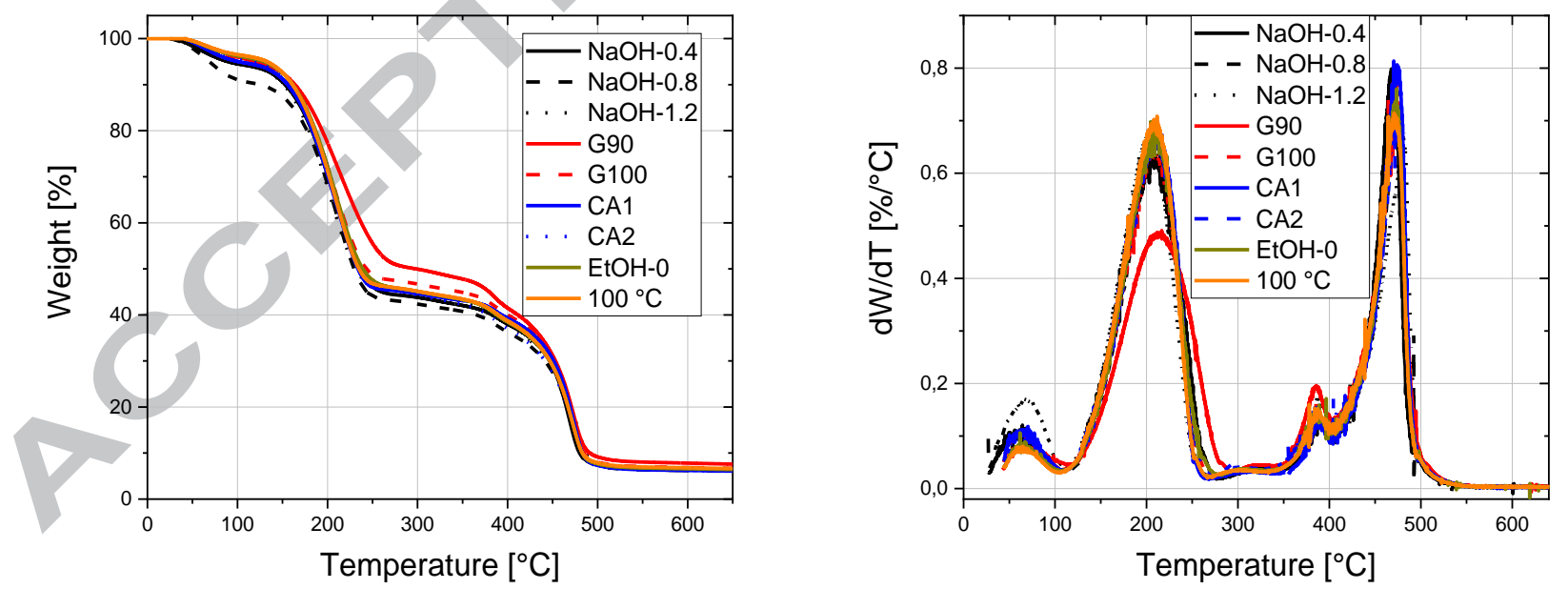

Figure 6. Thermogravimetric analysis of glycerol-silicone foams prepared using different conditions. The weight loss curve (left) and derivative of the weight loss (right) indicate four occurring processes. The first and second processes are related to liquid evaporation, while the third and fourth are related to polymer degradation. 


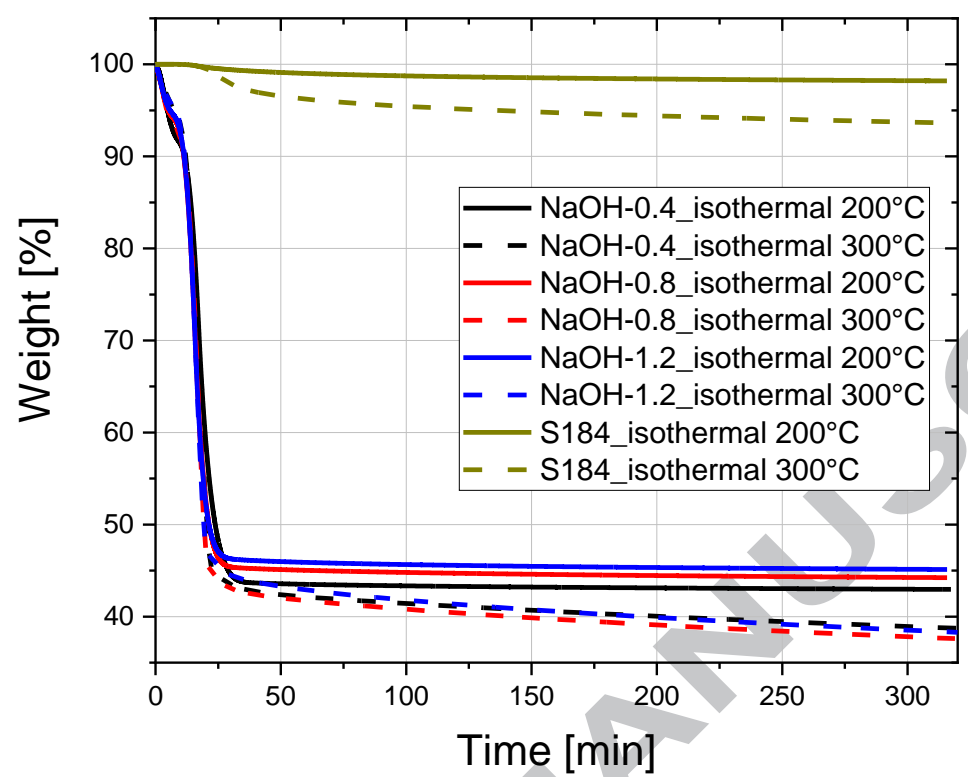

Figure 7. Isothermal thermogravimetric analysis of Sylgard 184 and glycerol-silicone foams containing different amounts of sodium hydroxide.

In the next step, different types of inorganic bases were evaluated with respect to their performance as foaming agents, namely lithium hydroxide, sodium hydroxide and potassium hydroxide (ordered from the weakest to the strongest). For each composition, $0.4 \mathrm{wt} \%$ solution in glycerol was prepared, and in the case of lithium hydroxide an additional $0.5 \mathrm{wt} . \%$ of water was added to facilitate dissolution of the base. Water in such low concentrations was proved to have an incremental effect on foaming. More information about the influence of water on the foaming process can be found in the Supplementary Information. The TG analysis presented in Figure 8 shows that the choice of base has a tremendous impact on the thermal stability of the foam, because the stronger the base, the lower the thermal stability. The sample with potassium hydroxide had a main degradation peak at $370^{\circ} \mathrm{C}$, sodium hydroxide at $470^{\circ} \mathrm{C}$ and lithium hydroxide at $505^{\circ} \mathrm{C}$. The 
main degradation peak of the sample $\mathrm{LiOH}-0.4$ occurred at only slightly lower temperature compared to pure Sylgard $184\left(550^{\circ} \mathrm{C}\right)$, which proves the good thermal stability of this composition.

The isothermal TGA confirmed that samples with lithium hydroxide and sodium hydroxide are very stable at $200^{\circ} \mathrm{C}$ and $300^{\circ} \mathrm{C}$, while the sample with potassium hydroxide exhibits a significant mass loss at $300^{\circ} \mathrm{C}$. Therefore, potassium hydroxide is considered too strong for the investigated systems. Importantly, it was noted that samples prepared with lithium hydroxide have significantly lower relative density compared to those with sodium hydroxide and potassium hydroxide (the highest density). Exactly the same mass amounts of each base were added to glycerol, which resulted in obtaining different molar amounts. This in turn is direct proof that even weak bases can trigger a reaction between the hydroxyl and silicon hydride groups and act as efficient blowing agents. This fact and all of the considerations presented in this section clearly indicate that lithium hydroxide performs best as a blowing agent producing low-density foams with good thermal stability. The only drawback of this compound is its rather poor solubility in glycerol, which has to be supported by adding low amounts of water, and possible human body intoxication when excessive amounts of the lithium cation enter the organism.[30] 

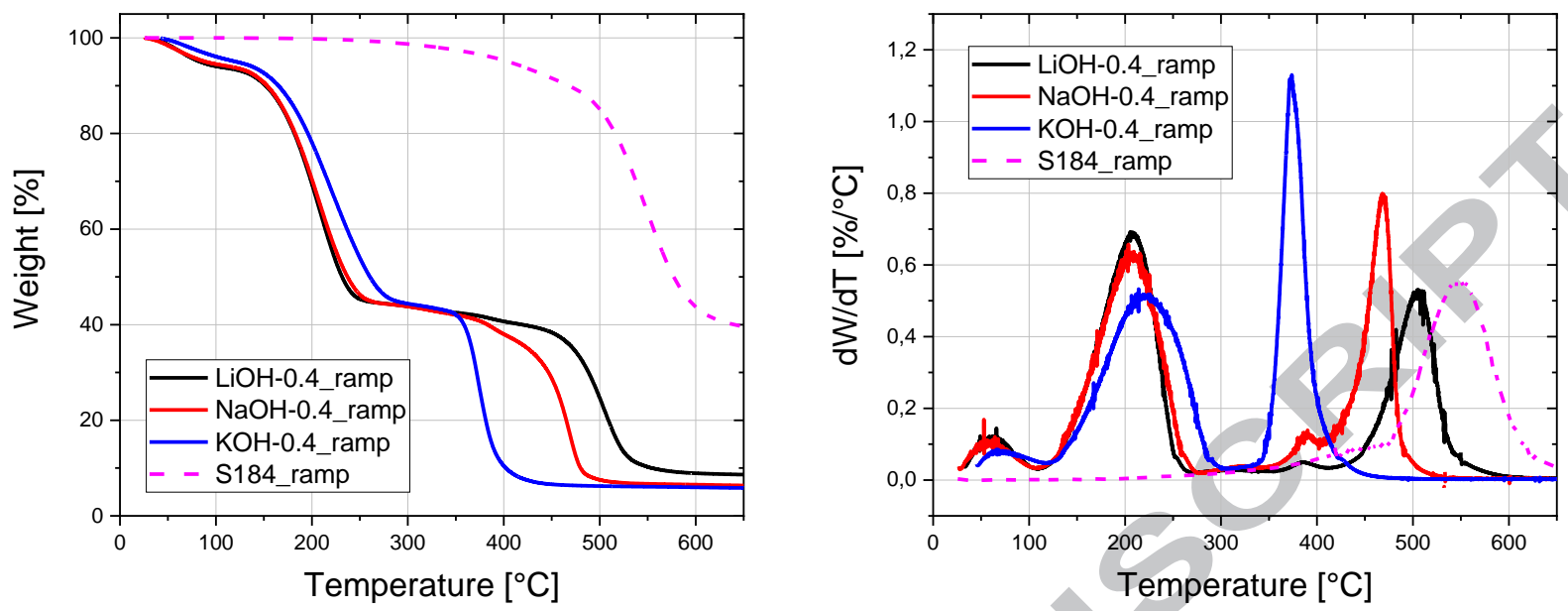

Figure 8. Thermogravimetric analysis of glycerol-silicone foams prepared using different inorganic bases. Weight loss curve (left) and derivative of the weight loss (right) prove the significant influence of the applied base on the thermal stability of the resulting foams.

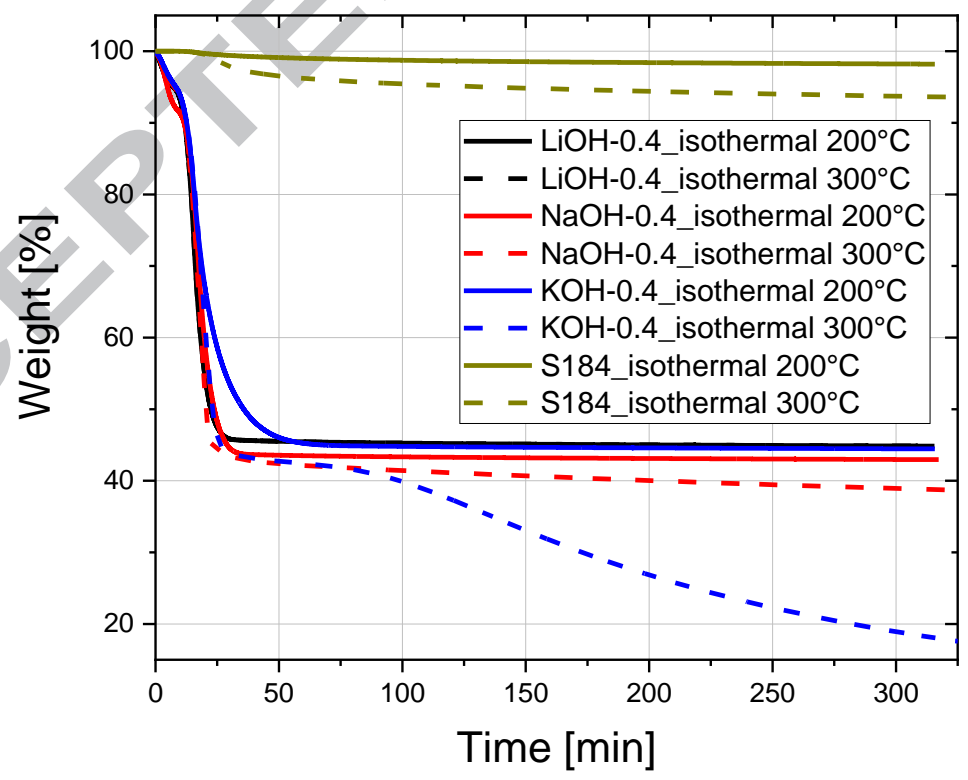

Figure 9. Isothermal thermogravimetric analysis of Sylgard 184 and glycerol-silicone foams containing different inorganic bases. 


\section{Conclusions}

A new method for preparing silicone foams has been presented. The foaming process involves incorporating the reaction between silicone hydride groups of the silicone prepolymer and hydroxyl groups of glycerol into the silicone prepolymer in the form of micrometer-size droplets. The balance between the foaming reaction and the hydrosilylation curing reaction of the silicone elastomer allows for the formation of novel 3-phase (solid, liquid, gas) materials. This simple and inexpensive method was proven herein to be highly reproducible and capable of generating foams in a broad range of densities. The density and compression modulus can be tuned precisely by varying several reaction parameters, such as base type, base content, curing agent content, ethanol content or curing temperature - and potentially others. The unusual 3-phase structure, and especially the presence of hydrophilic liquid domains acting as containers for active substances, enables a multitude of potential modifications, such as introducing hydrophilic flame-retardants or drugs for various substance delivery systems that are normally incompatible with hydrophobic silicones and silicone foams.

\section{Acknowledgements}

The authors acknowledge the generous funding received from The Independent Research Fund Denmark.

\section{References:}

[1] E. Yilgör, I. Yilgör, Prog. Polym. Sci. 39 (2014) 1165-1195.

[2] A.S. Fawcett, H.Y. So, M.A. Brook, Soft Matter 6 (2010) 1229-1237. 
[3] S.J. Choi, T.H. Kwon, H. Im, D. Il Moon, D.J. Baek, M.L. Seol, J.P. Duarte, Y.K. Choi, ACS Appl. Mater. Interfaces 3 (2011) 4552-4556.

[4] W.R. McCall, K. Kim, C. Heath, G. La Pierre, D.J. Sirbuly, ACS Appl. Mater. Interfaces 6 (2014) 19504-19509.

[5] J.J. Chrusciel, E. Lesniak, J. Appl. Polym. Sci. 119 (2011) 1696-1703.

[6] J. Zhang, E. Fleury, M.A. Brook, Green Chem. 17 (2015) 4647-4656.

[7] J.B. Grande, A.S. Fawcett, A.J. McLaughlin, F. Gonzaga, T.P. Bender, M.A. Brook, Polymer 53 (2012) 3135-3142.

[8] R. Verdejo, F. Barroso-Bujans, M.A. Rodriguez-Perez, J. Antonio de Saja, M.A. LopezManchado, J. Mater. Chem. 18 (2008) 2221-2226.

[9] M.A. Brook, Chem. Eur. J. 24 (2018) 8458-8469.

[10] A. Giustiniani, P. Guégan, M. Marchand, C. Poulard, W. Drenckhan, Macromol. Rapid Commun. 37 (2016) 1527-1532.

[11] A. Kovalenko, K. Zimny, B. Mascaro, T. Brunet, O. Mondain-Monval, Soft Matter 12 (2016) $5154-5163$.

[12] M.T. Grosse, M. Lamotte, M. Birot, H. Deleuze, Am. Chem. Soc. Polym. Prepr. Div. Polym. Chem. 49 (2008) 487-488.

[13] X. Liao, H. Xu, S. Li, C. Zhou, G. Li, C.B. Park, RSC Adv. 5 (2015) 106981-106988.

[14] R. Zargar, J. Nourmohammadi, G. Amoabediny, Biotechnol. Appl. Biochem. 63 (2016) 190199.

[15] J.W. Han, B. Kim, J. Li, M. Meyyappan, Appl. Phys. Lett. 102 (2013).

[16] E. Pedraza, A. Brady, C.A. Fraker, Cell Transplant. 22 (2013) 1123-1135.

[17] X. Zhao, L. Li, B. Li, J. Zhang, A. Wang, J. Mater. Chem. A 2 (2014) 18281-18287.

[18] D.H. Kim, M.C. Jung, S.H. Cho, S.H. Kim, H.Y. Kim, H.J. Lee, K.H. Oh, M.W. Moon, Sci. 
Rep. 5 (2015) 1-12.

[19] J. Shi, H. Zhang, J. Jackson, A. Shademani, M. Chiao, J. Mater. Chem. B 4 (2016) 74157422.

[20] P. Mazurek, S. Hvilsted, A.L. Skov, Polymer 87 (2016) 1-7.

[21] P. Mazurek, L. Yu, R. Gerhard, W. Wirges, A.L. Skov, J. Appl. Polym. Sci. 133 (2016) 1-8.

[22] P. Mazurek, M.A. Brook, A.L. Skov, Langmuir 34 (2018) 11559-11566.

[23] J.K. Kim, K. Taki, M. Ohshima, Langmuir 23 (2007) 12397-12405.

[24] P. Dayal, T. Kyu, J. Appl. Phys. 100 (2006) 1-6.

[25] I.D. Johnston, D.K. McCluskey, C.K.L. Tan, M.C. Tracey, J. Micromech. Microeng. 24 (2014) 035017.

[26] S. Hamdani, C. Longuet, D. Perrin, J.M. Lopez-Cuesta, F. Ganachaud, Polym. Degrad. Stab. 94 (2009) 465-495.

[27] M.A. Brook, Silicon in Organic, Organometallic, and Polymer Chemistry, John Wiley \& Sons, New York, 2000.

[28] H.K. Cammenga, F.W. Schulze, W. Theuerl, J. Chem. Eng. Data 22 (1977) 131-134.

[29] E. Ogliani, L. Yu, P. Mazurek, A.L. Skov, Polym. Degrad. Stab. 157 (2018) 175-180.

[30] M.P. Freeman, S.A. Freeman, Am. J. Med. 119 (2006) 478-481. 
Highlights:

- A new method for preparing silicone elastomeric foams has been developed

- The foaming process is simple, cost-efficient and reproducible

- The foaming can be precisely controlled to obtain desired foam density and rigidity

- The foams comprise additionally of micro-size glycerol domains

- Glycerol domains can act as containers for hydrophilic active substances 
Graphical abstract

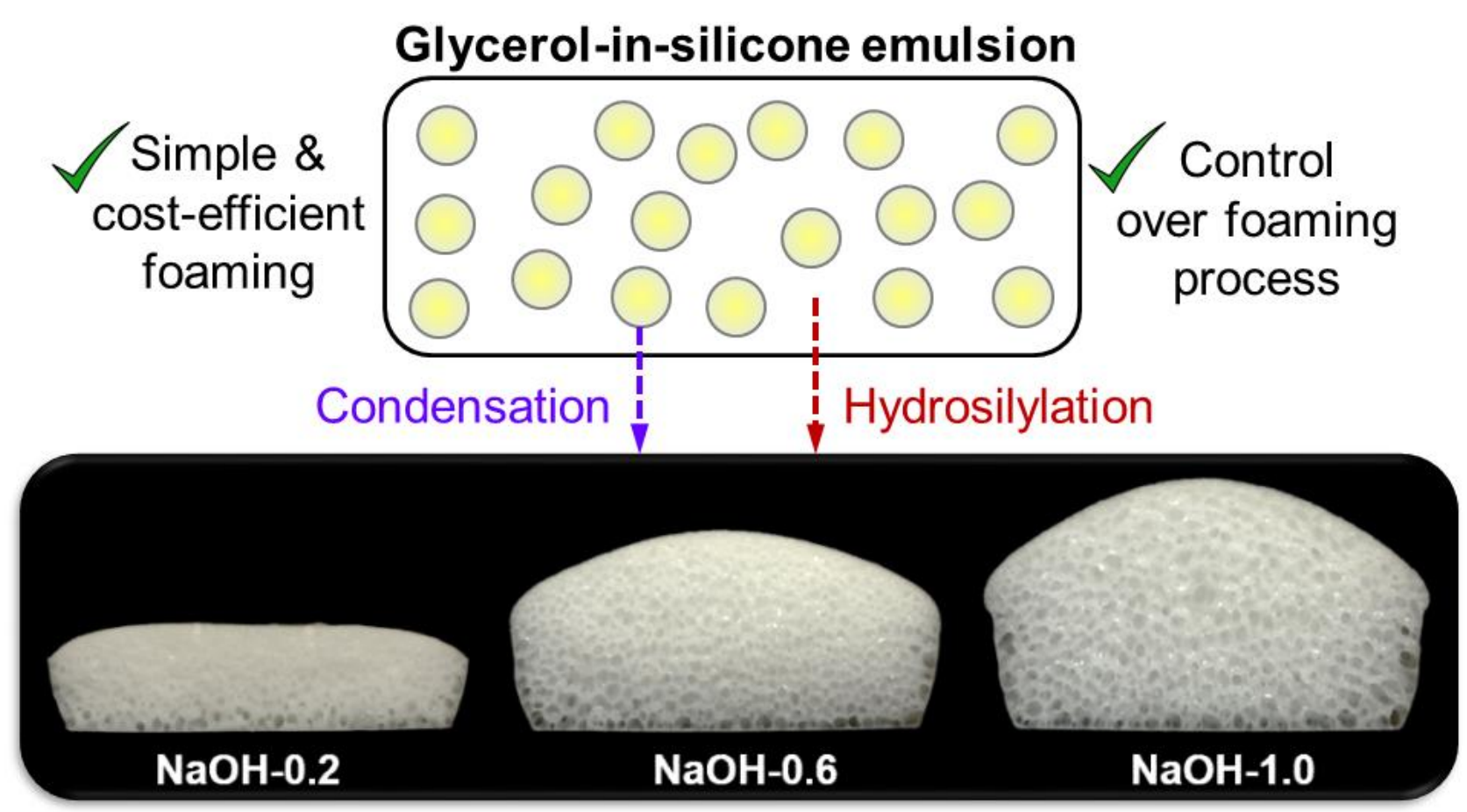

Tunable glycerol-silicone foams 